\title{
Positive and Negative Peer Contagion In Relation To Quality of Friend and Friendship
}

\author{
Prerna $^{1}$, Naved Iqbal ${ }^{2}$, Akash Kumar Mahato ${ }^{3}$
}

\section{ABSTRACT}

Peer contagion describes a mutual influence process that occurs between an individual and a peer and includes behaviors and emotions that potentially undermine one's own development or cause harm to others. The influence process often occurs outside of awareness; participants may not intend to influence their peers, but they engage in relationship behaviors that satisfy immediate needs for an audience or companionship, and these behaviors inadvertently influence themselves or others. It can be of two types positive and negative peer contagion. Negative peer contagion include- aggression where as positive would include altruistic behavior. Different ways to reduce peer contagion would that include evaluation of aggression, intervention strategies for youth. The present study conducted on 250 adolescents (age between 13 to15). Then on the basis of screening total number of 120 subjects were selected and divided into two equal groups of 60 subjects; each group had 30 low and 30 high quality of friendship group. They were selected from different schools of South Delhi. Tools used in the study are Aggression Questionnaire, Self-report altruistic scale (SRA), Quality of friendship questionnaire; Quality of friend (Interview schedule).The result suggested that there is no interaction between quality of friend and the quality of friendship in the positive peer contagion. But desirable friend and undesirable friend and high and low quality of friendship can distinguished on the positive peer contagion. On the negative peer contagion there is interaction between the quality of friendship and quality of friend and also high quality of friendship is highly related to it, also negative peer contagion is more related to undesirable friend.

Keywords: Quality of Friendship, Peer Contagion, Aggression, Altruism

The term peer contagion describes a mutual influence process that occurs between an individual and a peer and includes behaviors and emotions that potentially undermine one's own development or cause harm to others. Examples of peer contagion include aggression, bullying, weapon carrying, disordered eating, drug use, and depression .The influence process often occurs outside of awareness; participants may not intend to influence their peers, but they engage in relationship behaviors that satisfy immediate needs for an audience or companionship, and these

\footnotetext{
${ }^{1}$ M.Phil Trainee Clinical Psychology, AIBAS, Amity University, Rajasthan

${ }^{2}$ HOD \& Professor, Department of Psychology, Jamia Millia Ialamia, New Delhi

${ }^{3}$ Assistant Professor, AIBAS, Amity University, Rajasthan (C) 2015 I Prerna, N Iqbal, A Mahato; licensee IJIP. This is an Open Access Research distributed under the terms of the Creative Commons Attribution License (http://creativecommons.org/licenses/by/2.0), which permits unrestricted use, distribution, and reproduction in any Medium, provided the original work is properly cited.
} 
behaviors inadvertently influence themselves or others. Peer contagion occurs in natural settings involving peer interaction and can also be an outcome of intervention and educational programs that aggregate children and adolescents. Several mechanisms of peer contagion have been proposed. Among them is deviancy training, which involves the interpersonal dynamic of mutual influence during which youth respond positively to deviant talk and behavior. As applied to peer contagion, the deviancy training process is characterized by give-and-take exchanges between friends that promote deviant actions (e.g., past stories of deviant acts, suggestions for future behavior, what ifs) and elicit positive responses, such as laughter (Dishion \& Tipsord (2011).

\section{Negative peer contagion}

The effects of peers on aggression and antisocial behavior in childhood and adolescence, and on symptoms of emotion dysregulation, (Emotion dysregulation, emotional behavior that is in congruent with the situation or potentially undermines development, such as angry outbursts, extreme sadness and depression, or debilitating fear and anxiety) such as depression in adolescence.

\section{Childhood Aggression}

The actual time spent interacting with age mates surpasses the time spent with parents .During early and middle childhood, gender seems to be the most salient dimension organizing peer affiliations, reflecting the dominant and implicit interest in reinforcing values and norms associated with one's gender identity(Adam et.al, 2005). In a study girls at play in preschool and found that girls 'affiliations with aggressive children increased the probability of the girls' future aggression, and that changes in problem behavior in early childhood were predicted by affiliations with aggressive male and female children(Allen et.al, 2008). The dynamic interchanges among boys in preschool settings, revealing that responses to aggression in boys on the preschool playground formed the basis for learning and amplification of aggression. In these interactions, a successful aggressive overture in response to peer conflicted to future aggression with peers on the playground (Dijkstra et. al, 2010). Aggressive preschoolers preferred one another in play, and as would be expected, such play led to later increases in aggressive behavior. The social-cognitive map, provide procedure for studying peer relationships and cliques, revealing the complexity and structure of peer networks in the middle childhood years.(Cohen et.al, 2001).In a systematic studies, aggressive children, boys in particular, were often found to be central to the core social cliques in the classroom despite the fact that they were often socially rejected by many classmates. Rejection by peers because of aggression depends on the overall level of aggression in the school.(Trembley et.al ,2000)Isolating the social interaction processes (i.e., microsocial processes) underlying such effects at this age is as difficult as it is rare. This important study suggests that the mechanisms of contagion may also include negative reinforcement arrangements, in that children may collectively learn aggression in peer contexts in which "winning" a fight is the dominant problem-solving strategy, and this in turn increases the likelihood of future aggression. These findings suggest that adult structure and supervision of 
peer environments is likely one of the key moderators of peer contagion effects (Warren et. al, 2005)

\section{Positive peer contagion}

Although Dishon and Tipsord (2011) have mentioned less about positive peer contagion. Peers influence each other in negative ways; peers can also influence each other in positive ways. One can safely assume that peer contagion processes happen for positive behaviors, such as helping others. The fact that peer relationships are so important during adolescence suggests that adults must find ways to promote positive values and behaviors in those relationships. Positive peer influence to more fully understand how children and adolescents influence each other and to gain insight into how we might decrease the negative outcomes of peer contagion and increase positive peer influences. Peer influence is inevitable and thus, to reduce deviant peer influence, society must promote non deviant values and strengthen youths' positive connections to peers and adults. The characteristics of schools and communities and children's and adolescents' experiences within those domains have a significant impact. (Hanish et.al, 2005)

\section{Friendship Quality}

The old proverb says, "A friend in need is a friend indeed." That is, friends help and share with each other. Children agree with adults that these types of prosocial behavior are expected among friends. Children also agree with adults that good friends praise each other's successes and encourage each other after failures, thereby bolstering each other's self-esteem. Some features of high-quality friendships are recognized by adolescents but not by young children. Adolescents often say that best friends tell each other everything, or disclose their most personal thoughts and feelings. These personal self-disclosures are the hallmark of an intimate friendship. Adolescents also say that friends will stick up for one another in a fight, demonstrating their loyalty.

\section{Direct Effects of Friendship Quality}

Most writers on friendship have assumed that high-quality friendships have positive effects on children, fostering their self-esteem, improving their social adjustment, and increasing their ability to cope with stressors. Moreover, the correlations of friendship quality with indicators of social adjustment are consistent with that assumption. For example, among early adolescents, having friendships with more positive features correlates with greater involvement in school, higher self-perceived social acceptance, and higher general self-esteem .Still, a significant correlation between two variables is only weak evidence that one affects the other. (Hawley et.al, 2003)

\section{Indirect Effects of Friendship Quality}

For decades, researchers from a variety of disciplines have tested the hypothesis that children and adolescents are influenced by the attitudes and behaviors of their peers. Not all studies have provided support for the hypothesis, but the available data convincingly show that close friends influence many facets of children's and adolescents' social behavior and adjustment. In most 
studies, researchers have not assessed the quality of the friendships among the peers who were influencing one another. But when the issue has been raised, researchers have often suggested that the magnitude of friends' influence should be affected by the quality of their friendships. In this way, friendship quality can have an indirect effect on children's social developmentaffecting how much children are influenced by their friends' characteristics. By examining friendship interactions of youth representing differing developmental patterns of antisocial behavior, this study also aimed to better elucidate the characteristics and influence processes associated with both deviant and normative friendships. (Miller et.al, 2002)

\section{Deviant Friendships}

Several researchers have identified unique developmental histories of problem behavior in adolescents that may be important when examining the role of peer relationships in the development of antisocial behavior. Antisocial behavior persists into adolescence in approximately half the males who engage in it during childhood. (Goodnight et.al, 2006)

\section{Normative Friendships}

Much of the work on understanding the quality of friendships and influence has focused on normative children and adolescents. In general, we know that there is positive friendship qualities associated with positive adjustment in youth. Academic success and school engagement have been found to be associated with positive friendship qualities such as intimacy and prosocial friendship behaviors. (Mrug et.al, 2009)Other positive developmental outcomes (i.e., high levels of self-esteem, adjustment, coping) are also associated with high quality friendships. Quality (characteristics) of the friend affect the quality of friendship, it influences whether the friend is good (in academic, sincere, helpful, supportive) or bad (bullying, aggressive, drug use, rebellious).

The aim of the study was to find out positive and negative peers contagion in relation to quality of friend and quality of friendship.

\section{METHODOLOGY}

The present study conducted on 250 adolescents (age 13-15) for screening. Then on the basis of scores, 60 undesirable \& 60 undesirable types of friend group were selected, each group had 30 low and 30 high quality of friendship group. Thus, the final sample was of 120 participants. They were selected from different schools of South Delhi. A 2x2 factorial design was used in the present investigation. Factor one is quality of friend and it has two levels, i.e., good and bad friend. Factor two is quality of friendship and it also has two levels, i.e., low and high quality of friendship. 


\section{TOOLS:}

- Aggression Questionnaire, Aggression is measured by Aggression Questionnaire developed by Buss and Perry. (1992). Its 34 items are scored on the following five scales, Physical Aggression, Verbal Aggression, Anger, Hostility, and Indirect Aggression. A Total score is also provided, along with an Inconsistent Responding Index (a form of a lie scale). Standardization is based on a sample of 2,138 individuals, aged 9 to 88, and norms are presented in three age sets, 9 to 18, 19 to 39, and 40 to 88.The reliability co-efficient Cronbach's alpha was found to be 0.988 on the sample of the present study.

- Self-report altruistic scale- Altruistic behavior will measured by Self Report Altruistic Scale developed by Rushton, Singh \& Khanna (1981).It has 20 items which is measured in 5 point scale .The goal was to measure altruism in a behaviorally concrete manner. The scale was found to be psychometric stability, internal consistency discriminant validity.The reliability co-efficient Cronbach's alpha was found to be 0.983 on sample of the present study.

- Quality of friendship questionnaire: Quality of friendshipwill be measured by quality of friendship scale developed by Peihler and Dishion.(2007).It will be used to determine high quality and low quality of friendship. This scale has positive friendship features and negative friendship features. Positive friendship features consist of 5 items whereas Negative friendship feature consists of 5 items and the subjects have to respond on 5 point scale.

\section{Procedure:}

Subjects were contacted individually from different schools of South Delhi. Scales of quality of friendship, aggression, altruistic behavior, problematic behavior and interview schedule for assessing the quality of friend were administered to 250 participants of class $8^{\text {th }}, 9^{\text {th }}$ and $10^{\text {th }}$. Then on the basis of scores, 60 good \& 60 bad types of friend group were selected, each group had 30 low and 30 high quality of friendship group. Then these groups were compared on negative (aggression) and positive contagion (altruistic behavior).The quality of friend was evaluated on the basis of Indian social norms. The data was sort on basis of the scores of quality of friend that is; desirable type has been assigned to those who scored below 5 and undesirable type has been assigned to those who scored above 5.In the quality of friendship those who scored above 30 assigned as high quality of friendship and those who scored below 30 assigned as low quality of friendship. 


\section{RESULT TABLES}

The results of the present study are reported in the following section. Keeping in view the design and objectives of this study, the obtained results were analyzed using the two-way Analysis Of Variance (ANOVA) followed by the $t$ test. The obtained results are being presented in the following table.

Table 1: Comparison of different groups on positive peer contagion (altruism)

\begin{tabular}{|l|l|l|l|l|l|l|}
\hline & $\begin{array}{l}\text { Quality of } \\
\text { friendship }\end{array}$ & $\mathrm{N}$ & Mean & Std. Deviation & $\mathrm{t}$ & $\mathrm{p}$ \\
\hline Desirable & high & 30 & 67.60 & 5.26 & .928 & (NS) \\
low & 30 & 68.83 & 5.02 & .2 .92 & .01 \\
\hline Undesirable & high & 30 & 17.36 & 4.99 & 3.18 & \\
\hline
\end{tabular}

Table 1 show that significant difference was not found between high quality of friendship and low quality of friendship on altruism However, in the undesirable friend significant difference was found between high and low quality of friendship at 0.01 levels on altruism. High altruism group scored significantly higher than low altruism group.

Table 2: Comparison of different groups on negative peer contagion (physical aggression)

\begin{tabular}{|c|c|c|c|c|c|c|}
\hline & $\begin{array}{l}\text { Quality } \\
\text { of } \\
\text { friendship }\end{array}$ & $\mathrm{N}$ & Mean & Std. Deviation & $\mathrm{t}$ & $\mathrm{p}$ \\
\hline \multirow[t]{2}{*}{ Desirable } & high & 30 & 16.73 & 2.27 & \multirow{2}{*}{1.76} & \multirow[t]{2}{*}{ NS } \\
\hline & low & 30 & 15.86 & 1.43 & & \\
\hline \multirow[t]{2}{*}{ Undesirable } & high & 30 & 54.73 & 1.85 & \multirow[t]{2}{*}{7.97} & \multirow[t]{2}{*}{0.01} \\
\hline & low & 30 & 48.46 & 3.88 & & \\
\hline
\end{tabular}

In the desirable friend Table 2 shows that significant difference was not found between high quality of friendship and low quality of friendship on physical aggression whereas, in bad type of friend, significant difference was found between high and low quality of friendship at 0.01 levels. In undesirable friend, high quality of friendship group scored significantly higher than low quality of friendship group on physical aggression. 
Table 3: Comparison of different groups on negative peer contagion (verbal aggression)

\begin{tabular}{|c|c|c|c|c|c|c|}
\hline & Quality & & & & & \\
\hline & $\begin{array}{l}\text { of } \\
\text { friendship }\end{array}$ & $\mathrm{N}$ & Mean & Std. Deviation & $\mathrm{t}$ & $\mathrm{p}$ \\
\hline \multirow[t]{2}{*}{ Desirable } & high & 30 & 8.80 & 1.39 & \multirow[t]{2}{*}{2.33} & \multirow[t]{2}{*}{0.05} \\
\hline & low & 30 & 8.03 & 1.12 & & \\
\hline \multirow[t]{2}{*}{ Undesirable } & high & 30 & 31.1 & 2.88 & \multirow[t]{2}{*}{4.08} & \multirow[t]{2}{*}{0.01} \\
\hline & low & 30 & 28.2 & 2.6 & & \\
\hline
\end{tabular}

In the desirable friend Table 3 shows that significant difference was found between high quality of friendship and low quality of friendship on verbal aggression at 0.05., between high and low quality of friendship at 0.01 levels on verbal aggression. In both good and undesirable friend, high quality of friendship group scored significantly higher than low quality of friendship group on verbal aggression.

Table 4: Comparison of different groups on negative peer contagion (anger)

\begin{tabular}{|l|l|c|c|c|c|c|}
\hline & $\begin{array}{l}\text { Quality } \\
\text { of } \\
\text { friendship }\end{array}$ & $\mathrm{N}$ & Mean & Std. Deviation & $\mathrm{t}$ \\
\hline Desirable & high & 30 & 14.3 & 1.44 & $\mathbf{2 . 1 3}$ & 0.05 \\
\cline { 2 - 6 } & low & 30 & 13.6 & 1.06 & & \\
\hline Undesirable & high & 30 & 40.16 & 2.52 & \multirow{2}{*}{2.7} & 0.01 \\
\cline { 2 - 5 } & low & 30 & 38.5 & 2.22 & & \\
\hline
\end{tabular}

In the desirable friend Table 4 shows that significant difference was found between high quality of friendship and low quality of friendship on problem behavior at 0.05 and between high and low quality of friendship at 0.01 levels. In both good and undesirable friend, high quality of friendship group scored significantly higher than low quality of friendship group on anger.

Table 5: Comparison of different groups on negative peer contagion (hostility)

\begin{tabular}{|c|c|c|c|c|c|c|}
\hline & $\begin{array}{l}\text { Quality } \\
\text { of } \\
\text { friendship }\end{array}$ & $\mathrm{N}$ & Mean & Std. Deviation & $\mathrm{t}$ & $\mathrm{p}$ \\
\hline \multirow[t]{2}{*}{ Desirable } & high & 30 & 11.15 & 1.69 & \multirow[t]{2}{*}{3.19} & \multirow[t]{2}{*}{0.01} \\
\hline & low & 30 & 10.16 & 1.53 & & \\
\hline \multirow[t]{2}{*}{ Undesirable } & high & 30 & 50.36 & 3.39 & \multirow[t]{2}{*}{3.6} & \multirow[t]{2}{*}{0.01} \\
\hline & low & 30 & 47.33 & 3.06 & & \\
\hline
\end{tabular}


In the desirable friend Table 5 shows that significant difference was found between high quality of friendship and low quality of friendship on hostility and between high and low quality of friendship at 0.01 levels. In both good and undesirable friend, high quality of friendship group scored significantly higher than low quality of friendship group on hostility.

\section{DISCUSSION}

The purpose of this study was to find out positive and negative peer contagion with respect to quality of friend and quality of friendship. . The participants included both the boys and girls and the age range taken was from 13 years to 15years. The quality of friendship was measured on the basis of two dimensions positive and negative friendship feature. The quality of friend was measured by interview schedule which was designed on the keeping in mind the Indian social norms of the contemporary society. The reliability of the collected data was obtained is 0.9 . The data were analyzed by using two - way ANOVA and t- test.

The desirable and undesirable friend group will differ on positive peer contagion (altruism) was supported by the present study. Positive peer contagion has significant difference in desirable friend and undesirable friend. The reason for such finding might be the adolescents who are good in studies are so very well versed with the values that they are ready for help others at any time. The high quality friendship and low quality friendship adolescents will differ on positive peer contagion was also supported by the present study. Positive peer contagion has significant difference in high Quality of friendship and low quality of friendship. The reason for such finding that the time which is important to give in any relationship is not given as much as needed to understand each other; therefore these adolescent have low quality of friendship. Positive peer contagion has no significant difference on the interaction of quality of friend and friendship. The reason for such finding might be in the case of desirable quality of friend the quality is friendship is low. This is may be due among student friendship values are not prioritized over the studies. Adolescent those are under good quality focus more on the academic than the values and quality of friendship.

Studies conducted by Dishion and Tipsord(2011) on the peer contagion stated that there is less researches on the subject matter as this area has not been explored much by the researcher the possibility of the reason for the rejection may not be clear too.

The desirable and undesirable friend group will differ on negative peer contagion (aggression) was supported by present study. Negative peer contagion has significant difference in desirable friend and undesirable friend. The interaction between quality of friend and friendship was seen in negative peer contagion. The reason for such finding might be those who are seen as undesirable friend generally have disorders related to eating, often show rebellious behavior and more over they have outburst of anger. All these things have developed in them because these adolescents are rejected by the society and by their own parents. The high quality friendship and low quality friendship adolescents will differ on negative peer contagion” was supported by 
present study. Negative peer contagion has significant difference on high and low quality of friendship. The reason may be that many adolescent believe that if they will not do as their bad friends are doing they will be thought as outdated; in order to maintain their up to date status in their group and hence there is seen high quality of friendship in this group. Negative peer contagion has significant interaction between quality of friend and friendship .The reason for this finding might be the following studies: Dishion and Tipsord (2011) in their research on peer contagion prove that negative peer contagion (disordered eating, problematic behavior and aggression) is related with quality friend and friendship. Piehler \& Dishion (2007) have researched on how relationship characteristics affect contagion processes is complex. Although some research finds that high-quality relationships are the most influential.

There will be comparison of different groups on negative peer contagion. This result might be due to fact that often there is group of adolescent who liked to be called as gang of the school or the society.

\section{CONCLUSIONS}

The result of present study suggested desirable friend and undesirable friend and high and low quality of friendship can distinguished on the positive peer contagion. On the negative peer contagion there is interaction between the quality of friendship and quality of friend and also high quality of friendship is highly related to it, also negative peer contagion is more related to un desirable friend.

\section{REFERENCES}

Adams, R.E., Bukowski, W.M., Bagwell, C. (2005). Stability of aggression during early adolescence as moderated by reciprocated friendship status and friend's aggression. Int. J. Behav. Dev., 29, 139-45.

Allen, J.P., \& Antonishak,, J . (2008). Adolescent peer influences, beyond the dark side. In M.J. Prinstein, \& K.A. Dodge (eds) Understanding Peer Influence in Children and Adolescents, pp. 141-60. New York, Guilford.

Buss, A.H., Perry, M., The Aggression Questionnaire. (1992)Journal of Personality and Social Psychology.,63,452-459.

Cohen, G.L., Prinstein, M.J. (2006). Peer contagion of aggression and health risk behavior among adolescent males, an experimental investigation of effects on public conduct and private attitudes. Child Dev., 77,967-83.

Dijkstra, J.K., Lindenberg, S., Veenstra, R., Steglich, C., Isaacs, J., et al. (2010). Influence and selection processes in weapon carrying in adolescence, the role of status, aggression, and vulnerability. Criminology. ,48,187-220.

Dishion, T.J., Nelson, S.E., Bullock, B.M. (2004). Premature adolescent autonomy, parent disengagement and deviant peer process in the amplification of problem behavior. $J$. Adolesc., 27,515-30.

Dishion, T.J., Nelson, S.E., Winter, C.E., Bullock, B.M. (2004). Adolescent friendship as a dynamic system, entropy and deviance in the etiology and course of male antisocial behavior. J. Abnorm., Child Psychol. 32,651-63. 


\section{Positive and Negative Peer Contagion In Relation To Quality of Friend and Friendship}

Dishion, T.J., Piehler, T.F., Myers, M.W., (2008). Dynamics and ecology of adolescent peer influences. .In M.J. Prinstein, \& K.A. Dodge , (eds) Understanding Peer Influence in Children and Adolescents, pp. 72-93. New York, Guilford.

Dijkstra, J.K., Lindenberg, S., Veenstra , R., Steglich ,C., Isaacs ,J., et al. (2010). Influence and selection processes in weapon carrying in adolescence, the role of status, aggression, and vulnerability. Criminology, 48,187-220

Dodge, K.A., Dishion, T.J., Lansford, J.E. (2006). Deviant peer influences in intervention and public policy for youth. Soc. Policy Rep. ,20,3-19.

Gardner, M., Steinberg, L.(2005). Peer influence on risk taking, risk preference, and risky decision making in adolescence and adulthood, an experimental study. Dev. Psychol., 41,625-35.

Gardner, T.W., Dishion, T.J., Connell, A.M. (2008). Adolescent self-regulation as resilience, resistance to antisocial behavior in the deviant peer context. J. Abnorm. Child Psychol. ,36,273-84.

Goodnight, J.A., Bates, J.E., Newman, J.P., Dodge, K.A., Petit, G.S. (2006). The interactive influence of friend deviance, disinhibition tendencies, and gender on the emergence of externalizing behavior during early and middle adolescence. J. Abnorm. Psychol. 34,57383.

Hanish, L.D., Martin, C.L., Fabes, R.A., Barcelo, H. (2005). Exposure to externalizing peers in early childhood, homophily and peer contagion processes. J. Abnorm. Child Psychol. ,33,267-81.

Hawley, P.H. (2003). Prosocial and coercive configurations of resource control in early adolescence, a case for the well-adapted Machiavellian. J. Dev. Psychol., 49,279-309.

Khanna,R., Singh, P., Rushton, J. P., Development of the Hindi version of a Self-Report Altruism Scale. Person. individ. 01\% Vol. 14, No. I, pp. 267-270, 1993 Printed in Great Britain.

Miller-Johnson, S., Coie, J.D., Maumary-Gremaud, A., Bierman, K., Conduct, Probl. Prev. Res. Group. (2002). Peer rejection and aggression and early starter models of conduct disorder. J. Abnorm. Child Psychol., 30,217-30.

Mrug, S., Windle, M. (2009). Moderators of negative peer influence on early adolescent externalizing behaviors, individual behavior, parenting, and school connectedness. $J$. Early Adolesc. ,29,518-40.

Piehler, T.F., Dishion, T.J. (2007). Interpersonal dynamics within adolescent friendship, dyadicmutuality, deviant talk, and patterns of antisocial behavior.Child Dev., 781,61124.

Prinstein, M.J., Wang, S.S. (2005). False consensus and adolescent peer contagion, examining discrepancies between perceptions and actual reported levels of friends' deviant and health risk behaviors. J. Abnorm. Child Psychol. ,33,293-306.

Rushton, J. P., Chrisjohn, R. D., \& Fekken, G. C. (1981). The altruistic personality and the selfreport altruism scale. Personality and Individual Differences, 2(4), 293-302.

Tremblay, R.E. (2000). The development of aggressive behavior during childhood, what have we learned in the past century? Int. J. Behav. Dev., 24,129-41.

Warren, K., Schoppelrey, S., Moberg, P., McDonald, M. (2005). A model of contagion through competition in the aggressive behaviors of elementary school students. J. Abnorm. Child Psychol. ,33,283-92. 